\title{
Modelling complex networks by random hierarchical graphs
}

\author{
M.Wróbel* \\ Institute of Mathematics, Maria Curie-Skłodowska University, Lublin, Poland
}

Received January 31, 2008

\begin{abstract}
Numerous complex networks contain special patterns, called network motifs. These are specific subgraphs, which occur oftener than in randomized networks of Erdős-Rényi type. We choose one of them, the triangle, and build a family of random hierarchical graphs, being Sierpiński gasket-based graphs with random "decorations". We calculate the important characteristics of these graphs - average degree, average shortest path length, small-world graph family characteristics. They depend on probability of decorations. We analyze the Ising model on our graphs and describe its critical properties using a renormalization-group technique.
\end{abstract}

Key words: random graphs, Ising model, complex networks, network motifs

PACS: $05.50 .+q, 05.70 . F h, 75.10 . N r, 89.75 .-k$

\section{Introduction}

A great number of complex networks that occur in nature have recently been found to contain characteristic sets of recurring subgraphs called network motifs [1-3]. These are small subgraphs (typically three- or four-node) that occur far oftener than in the randomized networks of ErdösRényi type. To find these motifs, one compares the subgraph content of the model representing a real network and the randomized network of Erdős-Rényi type with the same degree distribution.

In [3], the model is built up as a portion of $N$ elements of $\mathbb{Z}^{d}$ with periodic boundary conditions. A bond between the nodes $x$ and $y$ is placed at random according to a connectivity function $F(x, y)$, such that $\max F(x, y)=1$ and of range $1 \ll R^{d} \ll N$. The bond between the nodes $x$ and $y$ exists with probability $F(x, y)$. The authors find the number of appearances of all three- and four-node non-directed subgraphs in the model and compare them with the number of occurrences of the corresponding subgraphs in the random network of Erdős-Rényi type having $N$ nodes and the same degree distribution. It turns out that certain subgraphs (triangles, squares and aggregates of triangles) occur much oftener than in the Erdös-Rényi network. Those subgraphs are referred to as network motifs. Of course, different networks may display different network motifs, but a given motif can be used to characterize a family of networks. Many complex networks have a fractal-type structure, in which nodes form groups and then join the groups of groups, and so forth, starting from the lowest levels of organization (individual nodes) up to the level of the entire network [4]. This structure permits to consider useful network properties in a small part and then to expand them to the whole network.

In this paper, we choose one of the motifs found in [3] - the three-node complete non-directed graph. We build the family of random hierarchical graphs based on this motif, and analyze the important network characteristics, such as average degree, average shortest-path length, small world graph family [5], and the critical behavior of an Ising model.

Our family of graphs $\left\{\Lambda_{k}\right\}_{k \in \mathbb{N}}$ is generated in an iterative way. Here $k=1,2,3, \ldots$ denotes the level of the graph understood as a step of the construction. The initial graph (network motif), $\Lambda_{1}$, is the complete graph of order 3. Each step of the construction $k>1$ consists of two parts. First, we join 3 graphs of level $k-1$ (called units) in a way shown in figure 1. We obtain a Sierpiński

*E-mail: mwrobel@hektor.umcs.lublin.pl 
gasket-based graph, and this is a deterministic core of our model. In the second part of each step, we decorate the graph at random by adding independent bonds connecting every pair of distinct external nodes $a, b, c$ with probability $p$. This procedure yields two types of bonds: the nearestneighbor bonds (depicted by solid lines) and the long-range ones (dotted lines). Each graph has 3

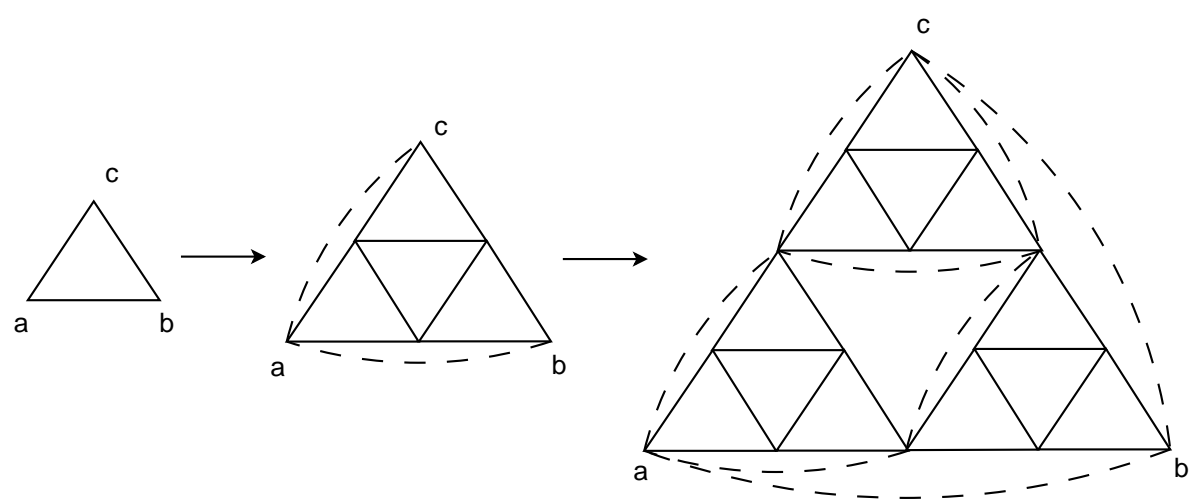

Figure 1. Construction of the graph $\Lambda_{3}$.

external nodes of a special purpose. Units of the same level are attached to them to form the unit of a higher level. In the figures we denote them by $a, b, c$. The rest of the nodes are called internal.

\section{Network characteristics}

Let $V_{k}$ and $E_{k}$ denote the sets of nodes and bonds, respectively. The latter set consists of two separate subsets $E_{k}(n n)$ and $E_{k}(l r)$, being the set of the nearest-neighbor and the long-range. It is easy to see, that

$$
\left|V_{k}\right|=\frac{3}{2}\left(3^{k-1}+1\right)
$$

is independent of $p$. For $E_{k}$, we obtain the expected value

$$
\left\langle\left|E_{k}\right|\right\rangle=3^{k}+\frac{3}{2}\left(3^{k-1}-1\right) p
$$

where the first term corresponds to the nearest-neighbor bonds $E_{k}(n n)$, and the second one is due to the long-range bonds $E_{k}(l r)$.

Notice, that if $p=0$ (nearest-neighbor bonds only), the number of bonds in $\Lambda_{k}$ is $3^{k}$. For $p=1$, one gets $\left|E_{k}\right|=\frac{3}{2} 3^{k}-\frac{3}{2}$, so decorating does not affect the asymptotics of $\left|E_{k}\right|$.

\subsection{Average degree}

Let $n_{k}(i)$ stand for the number of bonds ending at node $i \in V_{k}$. For each external node $i \in V_{k}$, one has $\left\langle n_{k}(i)\right\rangle=2+2(k-1) p$. Maximal degree in $\Lambda_{k}$ is achieved for the internal nodes which are the external ones in the unit of level $k-1$. One finds

$$
\max _{i \in \Lambda_{k}}\left\langle n_{k}(i)\right\rangle=4[1+(k-2) p] \quad k>1
$$

so for $p=1$ degree does not exceed $4(k-1)$.

In $\Lambda_{k}$, there exist 3 external nodes of degree $2+2(k-1) p$, and $3^{k-i}$ internal nodes of degree $4+4(i-1) p$ for $i=1,2, \ldots, k-1$. So the average expected value of degree in $V_{k}$ is the average of $\left\langle n_{k}(i)\right\rangle$ over all $i \in V_{k}$. This is

$$
\left\langle n_{k}\right\rangle=\frac{3(2+2(k-1) p)+\sum_{i=1}^{k-1}\left[3^{k-i}(4+4(i-1) p)\right]}{\frac{3}{2}\left(3^{k-1}+1\right)}=4+2 p-4 \frac{1+p}{3^{k-1}+1}
$$


which tends to $4+2 p$ in the limit $k \rightarrow \infty$.

\subsection{Average shortest-path length}

As the figure 2 suggests, it is convenient to introduce the following notations. The graph of level $k, k>1$, consists of 3 subgraphs of level $k-1$

$$
\Lambda_{k}=\Lambda_{k-1}^{a} \cup \Lambda_{k-1}^{b} \cup \Lambda_{k-1}^{c} .
$$

Every node $v \in V_{k}$ has a label pointing to a place in the graph

$$
v=\left\{\alpha_{1} \alpha_{2} \ldots \alpha_{k}\right\}, \alpha_{i} \in\{a, b, c\} .
$$

Each symbol corresponds to the choice of the triangle of previous level. Notice that every node, besides the external ones, has two labels. In the example, the node $v$ from figure 2 can be labelled by $\{$ bacca $\}$ or $\{$ bacac $\}$.

The distance $\rho_{k}(i, \gamma)$ between $i$ and $\gamma \in\left\{a_{k}, b_{k}, c_{k}\right\}$, measured in terms of the number of bonds along the path in $\Lambda_{k}$, is

$\rho_{k}(i, \gamma)=\left(1-\delta_{\alpha_{k} \gamma}\right)+\sum_{j=1}^{k-1} 2^{j-1}\left(1-\delta_{\alpha_{k-j} \gamma}\right)$.

Let $i \in \Lambda_{k-1}^{a}$ and $j \in \Lambda_{k-1}^{b}$. Then the distance between $i$ and $j$ is

$$
\rho_{k}(i, j) \leqslant \rho_{k-1}(i, b)+\rho_{k-1}(j, a) .
$$

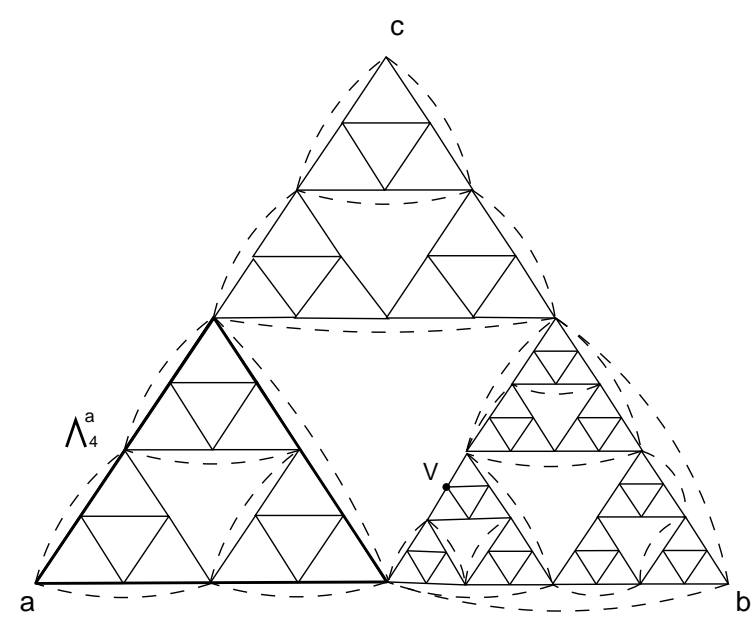

Figure 2. The graph of level 5.

Thus, for $p=0$, the average shortest-path length $\rho_{k}$ is

$$
\rho_{k}=\frac{\sum_{i, j \in V_{k}} \rho_{k}(i, j)}{\frac{1}{2}\left|V_{k}\right|\left(\left|V_{k}\right|-1\right)} \asymp 2^{k} .
$$

Notice that we do not include the distance from each node to itself in this average, but some authors (Newman [5]) do. This difference is negligible from practical point of view.

\subsection{Small world graph family}

For the last years, small-world networks have been studied intensively, see [5,6]. The family of graphs $\left\{\Lambda_{k}\right\}$ is a small world graph family if the diameter of $\Lambda_{k}$ (the maximal distance between the two nodes in $\Lambda_{k}$ ) scales logarithmically or slower with the graph size, that is,

$$
\exists C>0 \quad \operatorname{diam} \Lambda_{k} \leqslant C \log _{\left\langle n_{k}\right\rangle}\left|V_{k}\right| .
$$

In our model, for $p=0$, one has $\operatorname{diam} \Lambda_{k}=2^{k-1}$. So it is not the case. But for the decorated graph with $p=1$, we obtain $\operatorname{diam} \Lambda_{k}<k$ and corresponding constant is

$$
C=\left(\log _{6} 3\right)^{-1} \text {. }
$$




\section{The critical point of the Ising model}

The critical behavior of the Ising and Pots models certainly characterizes the network [7-9]. The Ising model for the diamond hierarchical lattice was considered in $[7,8]$. In [9], authors decorate this lattice and obtain exact results for the Ising model on it. We follow their example in describing our model.

The Ising model on our graph $\Lambda_{k}$ is defined by associating spin variables $\sigma_{i}= \pm 1$ to the nodes $i \in V_{k}$ and by the Hamiltonian

$$
-\beta \mathcal{H}=J \sum_{\langle i, j\rangle \in E_{k}(n n)} \sigma_{i} \sigma_{j}+K \sum_{\langle i, j\rangle \in E_{k}(l r)} \sigma_{i} \sigma_{j}+H_{\mathrm{B}} \sum_{\langle i, j\rangle \in E_{k}(n n)}\left(\sigma_{i}+\sigma_{j}\right)+H_{\mathrm{N}} \sum_{i \in V_{k}} \sigma_{i},
$$

where $J>0$ is the interaction for the nearestneighbor bonds and $K>0$ is the interaction constant for the long-range bonds. This Hamiltionian includes two types of magnetic field terms: $H_{\mathrm{B}}$ attached to bonds and $H_{\mathrm{N}}$ counted with nodes.

We use the renormalization-group transformation consisting of decimating the three internal nodes $\alpha, \beta, \gamma$ in the cluster shown in the figure 3. This transformation maps the Hamiltonian $-\beta \mathcal{H}\left(J, H_{\mathrm{B}}, H_{\mathrm{N}}, K, G\right)$ into a renormalized Hamiltonian $-\beta \mathcal{H}^{\prime}\left(J^{\prime}, H_{\mathrm{B}}^{\prime}, H_{\mathrm{N}}^{\prime}, K^{\prime}, G^{\prime}\right)$

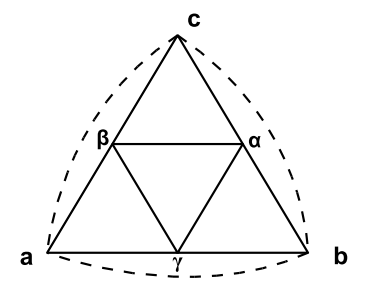

Figure 3. The cluster of level 2.

$$
-\beta \mathcal{H}^{\prime}=\sum_{\langle i, j\rangle \in E_{k}(n n)}\left(J^{\prime} \sigma_{i} \sigma_{j}+H_{\mathrm{B}}^{\prime}\left(\sigma_{i}+\sigma_{j}\right)+G^{\prime}\right)+H_{\mathrm{N}}^{\prime} \sum_{i \in V_{k}} \sigma_{i}+K^{\prime} \sum_{\langle i, j\rangle \in E_{k}(l r)} \sigma_{i} \sigma_{j} .
$$

The renormalized parameters are

$$
\begin{aligned}
J^{\prime} & =\frac{1}{8} \ln \left(\left(R_{0} R_{3}\right) /\left(R_{2} R_{1}\right)\right)+K, \\
K^{\prime} & =K, \\
H_{\mathrm{B}}^{\prime} & =\frac{1}{12} \ln \left(R_{3} / R_{0}\right), \\
H_{\mathrm{N}}^{\prime} & =H_{\mathrm{N}}, \\
G^{\prime} & =\frac{1}{24} \ln \left(R_{3} R_{0}\left(R_{2} R_{1}\right)^{3}\right)+4 G,
\end{aligned}
$$

where

$$
\begin{aligned}
& R_{0}=\left(x^{-3} y^{3}+3 x^{-3} y^{-1} z^{-2}+x y^{-5} z^{-4}+x^{9} y^{-9} z^{-6}\right) k^{3} g \\
& R_{1}=\left(x y^{5} z^{2}+x y+2 x^{-3} y+x^{-3} y^{-3} z^{-2}+2 x y^{-3} z^{-2}+x^{5} y^{-7} z^{-2}\right) k^{-1} g \\
& R_{2}=\left(x^{5} y^{7} z^{4}+2 x y^{3} z^{2}+x^{-3} y^{3} z^{2}+2 x^{-3} y+x y^{-1}+x y^{-5} z^{-2}\right) k^{-1} g \\
& R_{3}=\left(x^{9} y^{9} z^{6}+3 x y^{5} z^{4}+3 x^{-3} y z^{2}+x^{-3} y^{-6}\right) k^{3} g
\end{aligned}
$$

and the useful variables $x, y, z, g, k$ have a form

$$
x=\exp (2 J), \quad y=\exp \left(2 H_{\mathrm{B}}\right), \quad z=\exp \left(H_{\mathrm{N}}\right), \quad g=\exp (12 G), \quad k=\exp (K) .
$$

Here $G$ is an additive constant per bond, absent in the Hamiltonian (1), but always generated by the transformation, and $R_{j}$ corresponds to the partition function of the external nodes with $j$ spins equal to 1 and the rest $(3-j)$ equal to -1 .

The subspace $H_{\mathrm{B}}=H_{\mathrm{N}}=0$ is up-down symmetric and closed under the transformation (3), (4). Within this subspace we calculate the fixed point. Here $y=z=1$ and from (4) we obtain the following system of equations:

$$
\left\{\begin{array}{c}
x^{3}=\left(x^{9}+3 x+4 x^{-3}\right) k^{3} g \\
x^{-1}=\left(x^{5}+4 x+3 x^{-3}\right) k^{-1} g
\end{array}\right.
$$


Hence the final equation takes the form

$$
s=t \frac{s^{3}+3 s+4}{s^{2}+4 s+3}
$$

where $s=x^{4}$ and $t=k^{4}$.

If $t=1$ (the model without long-range bonds), we find only a fixed point $s=1$, which is stable and there are no critical points.

Solving the equation (6) for $t>1$ we obtain two solutions

$$
s_{1}=\frac{3+t-\sqrt{9+22 t-15 t^{2}}}{2(t-1)}, \quad s_{2}=\frac{3+t+\sqrt{9+22 t-15 t^{2}}}{2(t-1)} .
$$

So there are three types of behavior for the renormalization-group flows. For all $K$ lower than a threshold value $K_{\mathrm{c}}$ and for all $p \in(0,1]$ we can find $J$ such that the critical point exists. So the flows go to a continuous line of fixed points $J(K), K<K_{\mathrm{c}}$, with a distinct fixed point for each starting interaction $K$. When $K=K_{\mathrm{c}}$ there is one stable fixed point $J_{\mathrm{c}}\left(K_{\mathrm{c}}\right)=\frac{1}{8} \ln 3$, and there are no phase transitions. For $K>K_{\mathrm{c}}$ we can find sufficient small $p$, for which there exists $J(K)$ such that the critical point exists..

It is easy to see, that

$$
K_{\mathrm{c}}=\frac{1}{4} \ln \frac{9}{5}
$$

\section{References}

1. Milo R., Shen-Orr S., Itzkovitz S., Kashtan N., Chklovskii D., Alon U., Science, 2002, 298, 824-827.

2. Kashtan N., Itzkovitz S., Milo R., Alon U., Phys. Rev. E, 2004, 70, 031909.

3. Itzkovitz S., Alon U., Phys. Rev. E, 2005, 71, 026117.

4. Clauset A., Moore C., Newman M. Structural Inference of Hierarchies in Networks, In: Proceedings of the 23rd International Conference on Machine Learning, Workshop on "Statistical Network Analysis", Springer Lecture Notes in Computer Science (Pittsburgh, June 2006), also arXiv:physics/0610051v1 [physics.soc-ph] 9 Oct 2006.

5. Newman M.E.J., SIAM Review, 2003, 45, 167 - 256.

6. Barrat A., Weigh M., Eur. Phys. J. B, 2000, 13, 547-560.

7. Griffiths R.B., Kaufman M., Phys. Rev. B, 1982, 26, 5022-5032.

8. Bleher P.M., Žalys E., Commun. Math. Phys., 1989, 120, 409-436.

9. Hinczewski M., A. Nihat Berker, Phys. Rev. E, 2006, 73, 066126. 


\title{
Моделювання складних мереж з використанням випадкових
} ієрархічних графів

\author{
М.Врубель \\ Інститут математики, Університет Марії Кюрі-Склодовської Люблін, Польща \\ Отримано 31 січня 2008 р.
}

Багато комплексних мереж містять особливі шаблони, так звані мережеві мотиви. Вони є спеціальними підграфами, що з'являються частіше ніж у випадкових мережах типу Ердоша-Рені. Ми обрали один з таких шаблонів - трикутник, і побудували сімейство випадкових ієрархічних графів, визначених за гаскетом Серпінського з випадковими “декораціями”. Розраховані важливі характеристики таких графів - середній ступінь, середня довжина шляху, характеристики сімейства графів "тісного світу". Вони залежать від імовірності декорацій. Проаналізовано модель Ізінга на наших графах, описано її критичні властивості з використанням методу ренорм-групи.

Ключові слова: випадкові графи, модель зінга, складні мережі, мережеві мотиви

PACS: $05.50 .+q, 05.70 . F h, 75.10 . N r, 89.75 .-k$ 